\title{
Screening for drought tolerance in cultivars of the ornamental genus Tagetes (Asteraceae)
}

Raluca Cicevan, Mohamad Al Hassan, Adriana F Sestras, Jaime Prohens, Oscar Vicente, Radu E Sestras, Monica Boscaiu Drought tolerance was evaluated in twelve cultivars of three ornamental Tagetes species ( $T$. patula, $T$. tenuifolia and $T$. erecta). A stress treatment was performed by completely stopping watering of plants maintained in controlled greenhouse conditions. After three weeks, several plant growth parameters (length of the stems, fresh weight and water content), photosynthetic pigments (chlorophylls and carotenoids), osmolytes (proline, glycine betaine and total soluble sugars), an oxidative stress maker (malondialdehyde) and antioxidants (total phenolics and total flavonoids) were measured. Considerable differences in the evaluated traits were found among the control and drought stressed plants. Drought stress generally caused a marked reduction in plant growth and carotenoid pigments, and an increase in soluble solutes and oxidative stress. For most cultivars, proline levels in stressed plants increased between 30 and 70 -fold compared to the corresponding controls. According to the different measured parameters, on average $T$. erecta proved to be more tolerant to drought than $T$. patula and $T$. tenuifolia. However, a considerable variation in the tolerance to drought was found within each species. The traits with greater association to drought tolerance as well as the most tolerant cultivars could be clearly identified in a principal components analysis. Overall, our results indicate that drought tolerant cultivars of Tagetes can be identified at early stages using a combination of plant growth and biochemical markers. 


\section{Screening for drought tolerance in cultivars of the ornamental genus Tagetes}

2 (Asteraceae)

3

4 Raluca Cicevana, Mohamad Al Hassan ${ }^{\mathrm{b}}$, Adriana F. Sestras ${ }^{\mathrm{a}}$, Jaime Prohens ${ }^{\mathrm{c}}$, Oscar Vicente

5 Radu E. Sestras ${ }^{\text {a }}$, Monica Boscaiud,*

6

7 a Faculty of Horticulture, University of Agricultural Sciences and Veterinary Medicine Cluj-

8 Napoca, 3-5 Manastur str., 400372 Cluj-Napoca, Romania

9 b Instituto de Biología Molecular y Celular de Plantas, Universitat Politècnica de València, 10 Camino de Vera s/n, 46022 Valencia, Spain

$11^{\mathrm{c}}$ Instituto de Conservación y Mejora de la Agrodiversidad Valenciana, Universitat Politècnica de 12 València, Camino de Vera s/n, 46022 Valencia, Spain

13 d Instituto Agroforestal Mediterráneo, Universitat Politècnica de València, Camino de Vera s/n, 1446022 Valencia, Spain

16 * Corresponding author, E-mail:mobosnea@eaf.upv.es, Tel.: (+34) 963879253, Fax: $(+34)$ $17 \quad 963879269$

18 E-mail addresses: raluca.cicevan@gmail.com (Raluca Cicevan), moalhas@posgrado.upv.es 19 (Mohamad Al Hassan), adriana.sestras@usamvcluj.ro (Adriana F. Sestras), jprohens@btc.upv.es 20 (Jaime Prohens), ovicente@ibmcp.upv.es (Oscar Vicente), rsestras@usamvcluj.ro (Radu E. 21 Sestras),mobosnea@eaf.upv.es (Monica Boscaiu) 


\section{Abstract}

27 Drought tolerance was evaluated in twelve cultivars of three ornamental Tagetes species $(T$. 28 patula, T. tenuifolia and T. erecta). A stress treatment was performed by completely stopping 29 watering of plants maintained in controlled greenhouse conditions. After three weeks, several 30 plant growth parameters (length of the stems, fresh weight and water content), photosynthetic 31 pigments (chlorophylls and carotenoids), osmolytes (proline, glycine betaine and total soluble 32 sugars), an oxidative stress maker (malondialdehyde) and antioxidants (total phenolics and total 33 flavonoids) were measured. Considerable differences in the evaluated traits were found among 34 the control and drought stressed plants. Drought stress generally caused a marked reduction in 35 plant growth and carotenoid pigments, and an increase in soluble solutes and oxidative stress. 36 For most cultivars, proline levels in stressed plants increased between 30 and 70-fold compared 37 to the corresponding controls. According to the different measured parameters, on average $T$. 38 erecta proved to be more tolerant to drought than $T$. patula and T. tenuifolia. However, a considerable variation in the tolerance to drought was found within each species. The traits with greater association to drought tolerance as well as the most tolerant cultivars could be clearly identified in a principal components analysis. Overall, our results indicate that drought tolerant

42 cultivars of Tagetes can be identified at early stages using a combination of plant growth and 43 biochemical markers.

\section{Abbreviations}

46 Car carotenoids

47 Chl a+b total chlorophylls

48 FW fresh weight

49 GB glycine betaine

50 MDA malondialdehyde

51 Pro proline

52 SL stem length

53 TF total flavonoids

54 TPC total phenolic compounds

55 TSS total soluble sugars

WC water content 
57

58

59

60

61

62

63

64

65

66

67

68

69

70

71

72

WS water stress

8

(1)

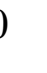

\section{Introduction}

1

62

63

The genus Tagetes L. (Asteraceae) includes 53 annual and perennial species (The Plant List, 2013) native to the American continent, from SW United States to South America. Several Tagetes species, commonly called marigolds, are well-known ornamental and medicinal plants cultivated throughout the world. When used as ornamentals they are mostly cultivated in flower beds and borders of landscape settings or as cut flowers (Valdez-Aguilar et al., 2009). Regarding their medicinal interest, extracts of leaves or flowers have been used in different affections of skin, kidney or liver (Giri et al., 2011; Maity et al., 2011); many species have also an antiinflammatory action (Lokesh, 2009; Shinde et al., 2009), or are used to reduce hypertension and high levels of cholesterol (Raghuveer et al., 2011). Moreover, studies on different taxa of this genus proved their antimicrobial (Ruddock et al., 2011), insecticidal (Hollis et al., 2012), and nematicidal (Hussain et al., 2011) effects. Their economic importance is increased by their value as melliferous plants and their use in the cosmetic industry, or as a natural dye for textiles, and food products (Vasudevan et al., 1997; Jothi, 2008).

This study focuses on three Tagetes species

This study focuses on three Tagetes species that are used as bedding ornamentals in gardens and green areas but also as potted plants in terraces or balconies, and occasionally as cut flowers. The French marigold (T. patula L.), native from Mexico to Argentina and first reported in Europe from France (Adams, 2004), is now cultivated throughout the world. It is well acclimated to Mediterranean regions, where is one of the most common ornamental species. Most of the numerous cultivars which have been developed give plants that are small sized, usually not more than $40 \mathrm{~cm}$ tall, much branched, with dark green leaves and small floral heads. Tagetes erecta L., commonly known as African marigold - although it originates from Mexico 83 is also grown in many regions outside its native range. Plants of this species can reach up to 1.5 $4 \mathrm{~m}$ or even more in its native area, but the most commonly used cultivars are generally shorter, 85 with a height of 60-80 cm (Serrato-Cruz, 2004). Although plants with long stems are optimal for 86 making flower garlands, overgrowth leads to an unattractive plant appearance that hinders their

87 use in pots. For this reason, new commercial varieties of T. erecta are usually selected for shorter 
88 growth (Serrato-Cruz, 2004). The third species under study, T. tenuifolia Cav. or signet 89 marigold, with smaller leaves and floral heads, is less known but holds promise for development as a commercially important ornamental crop (Gilman and Howe, 1999).

Ornamental Tagetes species are common in Mediterranean areas. Climate change has

92 93 94

Mitigation of the global warming is a formidable challenge at present, and there is an urgent need of selecting more stress tolerant genotypes of cultivated plants (Gholinezhad et al., 2014). Considering that in the near future water will be a scarcer and more expensive resource and that irrigation will be more restrictively used, selection and diversification of stress tolerant cultivars should be a priority for contemporary ornamental horticulture (Niu et al., 2006). In addition, on many occasions, potted plants for home or garden decoration suffer from drought stress due to a lack of regular watering by customers. Traditionally, selection of drought tolerant cultivars was done by directly growing plants under water stress conditions and comparing their growth and reproductive parameters with those measured in plants in the control treatments. Although this approach is reliable and has been successfully applied, it requires a long period of experimentation. Nowadays, faster screening methods are available (Mantri et al., 2014). Several of these have been already applied in Tagetes, such as testing the capacity of seeds to germinate in conditions of osmotic stress, simulated by PEG (Cicevan et al., 2015), or the in vitro selection of drought tolerant clones (Mohamed et al., 2000). A tool of remarkable utility, quick and detectable in very early stages of plant growth is the use of stress biochemical markers. This wide category comprises numerous compounds, easy to be quantified (Ashraf and Harris, 2004; Schiop et al., 2015), which after a brief exposure to stress suffer a change in their concentration in the plants, either increasing or decreasing with respect to the values registered in the controls. Optimal markers for screening the drought tolerance of crops are those related to degradation of 
119 photosynthetic pigments (Bijanzadeh and Emam, 2010; Mafakheri et al., 2010; Siddiqui et al., 120 2015), or osmolytes that are usually synthesised in conditions of cell dehydration as it occurs 121 when salinity or water stresses are applied (Sofo et al., 2004; Talukdar, 2013). Drought, as many 122 other abiotic stresses (high salinity, extreme temperatures), results in the enhanced generation of 123 reactive oxygen species (ROS). These secondary metabolites are continuously produced in plants 124 as by-products of aerobic metabolism, but under environmental stress conditions their amount 125 may largely increase, leading to oxidative stress (Van Breusegem and Dat, 2006). Consequently, 126 a general response to abiotic stress in plants is based on the activation of enzymatic and nonenzymatic antioxidant systems; the latter category including many flavonoids and other phenolic 128 compounds (Apel and Hirt 2004). If drought stress is prolonged beyond the tolerance limits of each genotype, ROS production surpasses the limits of scavenging action of the antioxidant systems, leading to the oxidation of the amino acid residues in proteins, the unsaturated fatty acids in cell membranes, and DNA molecules, causing extensive cellular damage and eventually plant death (Halliwell, 2006).

The aim of this work was two-fold: first, the identification of marigold tolerant cultivars,

134 based on their relative growth inhibition under severe drought conditions; and, second, to establish which biochemical responses are the best indicators of stress in Tagetes. The achievement of this latter objective may allow setting up protocols for quick evaluation of drought tolerance in Tagetes on the basis of biochemical markers.

\section{Material and methods}

\subsection{Plant material}

The cultivars selected for this study were purchased from local companies in Romania

144 (Agrosem) and Hungary (Kertimag) and comprised five cultivars of T. patula ('Bolero', 'Orange 145 Flame', 'Orion', 'Robuszta', and 'Szinkeverek'), four of T. tenuifolia ('Luna Gold', 'Luna 146 Lemon', Luna Orange', and 'Sarga'), and three of T. erecta ('Alacsony Citromsarga', 147 'Aranysarga', and 'Cupid Golden Yellow'). 
150

All seeds were sown directly into a moistened mixture of peat (50\%), perlite $(25 \%)$ and vermiculite $(25 \%)$ in $1 \mathrm{~L}$ pots $(\varnothing=11 \mathrm{~cm})$. The substrate was kept moderately moist, using

153 Hoagland nutritive solution. Three weeks after seedling emergence, a water stress treatment was initiated by completely stopping irrigation, maintaining a control treatment in which plants were watered twice a week with Hoagland nutritive solution $(125 \mathrm{~mL}$ per pot). All experiments were conducted in a controlled environment chamber in a greenhouse, under the following conditions: long-day photoperiod (16 hours of light obtained by supplementing natural light with artificial light), temperature of $23^{\circ} \mathrm{C}$ during the light period and $17^{\circ} \mathrm{C}$ during the dark period. Air humidity ranged between $50-80 \%$ during the course of the experiment. Three weeks after the initiation of treatments, when water stressed plants were already clearly affected, all material was harvested and the following growth parameters were determined: stem length (SL; cm), fresh weight of the leaves (FW; g), dry weight of the leaves (DW, g) and water content (WC; \%) (Gil et al., 2014).

\subsection{Photosynthetic pigments} and Welburn (1983). Basically, $100 \mathrm{mg}$ fresh plant material was crushed and extracted with 30 $\mathrm{ml} \mathrm{80 \%} \mathrm{ice-cold} \mathrm{acetone} \mathrm{prior} \mathrm{to} \mathrm{being} \mathrm{vortexed} \mathrm{and} \mathrm{centrifuged.} \mathrm{The} \mathrm{supernatant} \mathrm{was} \mathrm{separated}$ and its absorbance was measured at $663 \mathrm{~nm}\left(\mathrm{~A}_{663}\right), 646 \mathrm{~nm}\left(\mathrm{~A}_{646}\right)$, and $470 \mathrm{~nm}\left(\mathrm{~A}_{470}\right)$, using a Cadex model SB038 spectrophotometer (Cadex, Saint-Jean-sur-Richelieu, Canada). The concentration of each group of compounds was calculated according to the following equations: Chlorophyll $a\left(\mathrm{chl} \mathrm{a} ; \mu \mathrm{g} \cdot \mathrm{ml}^{-1}\right)=12.21 \cdot \mathrm{A}_{663}-2.81 \cdot \mathrm{A}_{646} ;$ Chlorophyll $b\left(\mathrm{chl} \mathrm{b} ; \mu \mathrm{g} \cdot \mathrm{ml}^{-1}\right)=$ $20.13 \cdot \mathrm{A}_{646}-5.03 \cdot \mathrm{A}_{663} ;$ Total chlorophylls $\left(\mu \mathrm{g} \cdot \mathrm{ml}^{-1}\right)=\mathrm{chl} \mathrm{a}+\mathrm{chl} \mathrm{b}$; Total carotenoids $\left(\mu \mathrm{g} \cdot \mathrm{ml}^{-1}\right)$

$174=\left(1000 \cdot \mathrm{A}_{470}-3.27 \cdot[\mathrm{chl} \mathrm{a}]-104 \cdot[\mathrm{chl} \mathrm{b}]\right) / 227$. The values were later converted to $\mathrm{mg} \cdot \mathrm{g}^{-1} \mathrm{DW}$.

\subsection{Osmolyte analysis}

177

Proline (Pro) content was determined in $100 \mathrm{mg}$ of fresh leaves by the ninhydrin-acetic acid method of Bates et al. (1973). Pro was extracted in 3\% aqueous sulfosalicylic acid, the extract was mixed with acid ninhydrin solution, incubated for $1 \mathrm{~h}$ at $95^{\circ} \mathrm{C}$, cooled on ice and then 
181 extracted with two volumes of toluene. The absorbance of the organic phase was measured at

$182520 \mathrm{~nm}$, using toluene as a blank. Pro concentration was expressed as $\mu \mathrm{mol} \mathrm{g}^{-1} \mathrm{DW}$.

183 Glycine betaine (GB) was determined in $100 \mathrm{mg}$ of dried plant material, according to the

184 method described by Grieve and Grattan (1983). The sample was ground with $2 \mathrm{ml}$ of Mili-Q

185 water, and then extracted with $4 \mathrm{ml}$ of 1, 2-dichlorethane; the absorbance of the solution was

186 measured at a wavelength of $365 \mathrm{~nm}$. GB concentration was expressed as $\mu \mathrm{mol} \mathrm{g} \mathrm{g}^{-1} \mathrm{DW}$.

187 Total soluble sugars (TSS) were quantified following Dubois et al. (1956). One hundred

$188 \mathrm{mg}$ of dried leaf material was ground and mixed with $3 \mathrm{ml}$ of $80 \%$ methanol on a rocker shaker

189 for 24-48 h. Concentrated sulfuric acid and 5\% phenol was added to the sample and the

190 absorbance was measured at $490 \mathrm{~nm}$. TSS contents were expressed as $\mathrm{mg}$ of glucose equivalents

$191 \mathrm{~g}^{-1}$ DW. All three osmolytes' wavelengths were measured using a Cadex model SB038

192 spectrophotometer.

193

194

\subsection{Oxidative stress marker and non-enzymatic antioxidants}

195

196

Malondialdehyde (MDA), total antioxidant flavonoids (TF), and total phenolic compounds (TPC) were determined in $80 \%(\mathrm{v} / \mathrm{v})$ methanol extracts of $100 \mathrm{mg}$ of dry plant material.

MDA, a final product of membrane lipid peroxidation and a reliable marker of oxidative stress (del Rio et al. 2005), was determined as reported by Hodges et al. (1999). Extracts were mixed with $0.5 \%$ thiobarbituric acid (TBA) prepared in 20\% TCA, (or with $20 \%$ TCA without TBA for the controls), and then incubated at $95^{\circ} \mathrm{C}$ for $20 \mathrm{~min}$. After stopping the reaction, the supernatant absorbance was measured at $532 \mathrm{~nm}$. The non-specific absorbance at 600 and 440 nm was subtracted and MDA concentration was calculated using the equations described in Hodges et al. (1999).

TF were measured following the method described by Zhishen et al. (1999), mixing the methanol extracts with sodium nitrite, followed by aluminum chloride and sodium hydroxide. The absorbance was measured at $510 \mathrm{~nm}$, and the amount of antioxidant total flavonoids was expressed in equivalents of catechin, used as standard (mg eq $\mathrm{C} \mathrm{g}^{-1} \mathrm{DW}$ ).

TPC were quantified as described in Blainski et al. (2013), by reaction with the Folin-

211 Ciocalteu reagent. The extracts were mixed with the reagent and sodium bicarbonate and left in 
212 the dark for $90 \mathrm{~min}$. Absorbance was recorded at $765 \mathrm{~nm}$, and the results expressed in

213 equivalents of gallic acid, used as standard (mg·eq $\left.\mathrm{GA} \mathrm{g}^{-1} \mathrm{DW}\right)$. All wavelengths were measured

214 using a Cadex model SB038 spectrophotometer.

215

216 2.6. Statistical analysis

217

218

219

Data were analyzed using the program Stagraphics Centurion v. XVI (Statpoint Technologies, Warrenton, Virginia, USA). The mean and standard error (SE) were calculated 220 from four replicates per cultivar (except for stem length, in which nine replicates were used). Mean values per species were calculated and the corresponding SE was calculated using cultivar means. The significance of the differences among control and drought stress treatments (expressed in percentage of variation over the control) for each variety was evaluated with

224 Student's $t$ tests. A multivariate principal components analysis (PCA) was performed using the cultivar means of both control and drought stress conditions in order to detect associations among the traits measured, as well as between the species and cultivars used. Data were standardized and Euclidean distances were used for the PCA.

\section{Results}

230

\subsection{Growth parameters}

232

The stem length was longer in T. tenuifolia than in T. patula and T. erecta (Table 1) and decreased in the three species as a result of the water stress treatment, when compared with the non-stressed controls. On average, the smallest reduction was registered in T. patula (20.2\%), and being pronounced in T. tenuifolia $(27.8 \%)$ and in $T$. erecta $(31.6 \%)$. Stem length reduction was statistically significant in all cultivars except in T. erecta 'Cupid Golden Yellow'. Large differences were observed among cultivars in the percentage of reduction of stem length (Table $2391)$.

Fresh weight (FW) decreased significantly under drought stress in all cultivars of $T$. patula and T. tenuifolia, but only in one of T. erecta (Table 1). On average, a strong reduction of

$24278.8 \%$ was registered in T. patula and of 79.2\% in T. tenuifolia, but of only $33.9 \%$ in $T$. erecta. 
243 In $T$. patula the smallest reduction was registered in the cultivar 'Robuszta' (68.4\%), whereas the 244 largest in cv. 'Orion' (86.7\%). Among cultivars of T. tenuifolia, the smallest loss in FW under 245 water stress was registered in plants of 'Luna Gold' (49.0\%), while the remaining three cultivars 246 showed a dramatic reduction of FW of more than $90 \%$ in respect to their control FW. Among the 247 T. erecta cultivars, the reduction in percentage ranged between 12.9\% in 'Cupid Golden Yellow' 248 and $43.9 \%$ in 'Alacsony Citromsarga'.

249 The water content (WC \%) also decreased in drought stressed plants when compared to 250 their respective controls in all cultivars (Table 1). The water loss was about $18 \%$ in T. patula 251 and $T$. erecta but reached $37.6 \%$ in T. tenufolia. Again, there were important differences within 252 species. Among the cultivars of $T$. patula, the smallest reduction of only $6.6 \%$ was observed in $253 \mathrm{cv}$. 'Bolero' and the highest of $27.4 \%$ in 'Orion'. In T. tenuifolia, the cultivar 'Luna Gold' 254 registered a small reduction of $7.4 \%$ but plants of cv. 'Luna Orange' lost 68\% of their water 255 content under drought. A smaller variation of water loss was found in T. erecta, from $12.3 \%$ in 256 'Alacsony Citromsarga' to $26.5 \%$ in 'Cupid Golden Yellow'. 
258 Tab. 1 Stem length (SL), fresh weight (FW), and water content percentage (WC) values (mean \pm SE) for control and drought stressed 259 (DS; three weeks without watering) plants of 12 cultivars of three species of Tagetes, and percentage of change of the drought stress 260 treatment over the control.

\begin{tabular}{|c|c|c|c|c|c|c|c|c|c|}
\hline \multirow[b]{2}{*}{ Cultivar } & \multicolumn{3}{|c|}{$\mathrm{SL}(\mathrm{cm})(\mathrm{n}=9)$} & \multicolumn{3}{|c|}{$\mathrm{FW}(\mathrm{g})(\mathrm{n}=4)$} & \multicolumn{3}{|c|}{$\mathrm{WC}(\%)(\mathrm{n}=4)$} \\
\hline & Control & DS & Change $(\%)^{\mathrm{a}}$ & Control & DS & Change $(\%)^{\mathrm{a}}$ & Control & $\mathrm{DS}$ & Change $(\%)^{a}$ \\
\hline \multicolumn{10}{|l|}{ T.patula } \\
\hline ‘Bolero’' & $14.50 \pm 0.89$ & $11.83 \pm 0.69$ & $-18.4^{*}$ & $5.32 \pm 0.30$ & $1.68 \pm 0.11$ & $-68.4^{* * *}$ & $91.91 \pm 0.18$ & $85.80 \pm 0.48$ & $-6.6^{* * *}$ \\
\hline 'Orange Flame’ & $10.83 \pm 0.47$ & $9.00 \pm 0.33$ & $-16.9^{* *}$ & $5.07 \pm 0.51$ & $1.38 \pm 0.07$ & $-72.8^{* * *}$ & $92.49 \pm 0.48$ & $73.97 \pm 0.50$ & $-20.0^{* * *}$ \\
\hline ‘Orion' & $9.11 \pm 0.25$ & $6.67 \pm 0.12$ & $-26.8^{* * *}$ & $8.79 \pm 0.51$ & $1.17 \pm 0.06$ & $-86.7^{* * *}$ & $91.25 \pm 0.32$ & $66.28 \pm 2.96$ & $-27.4^{* * *}$ \\
\hline 'Robuszta' & $8.17 \pm 0.28$ & $7.00 \pm 0.32$ & $-14.3^{*}$ & $5.19 \pm 0.46$ & $1.46 \pm 0.24$ & $-71.9^{* * *}$ & $91.84 \pm 0.21$ & $76.00 \pm 0.95$ & $-17.3^{* * *}$ \\
\hline 'Szinkeverek' & $9.84 \pm 0.17$ & $7.33 \pm 0.26$ & $-25.5^{* * *}$ & $8.68 \pm 0.28$ & $1.50 \pm 0.12$ & $-82.7^{* * *}$ & $92.14 \pm 0.26$ & $73.82 \pm 0.68$ & $-19.9^{* * *}$ \\
\hline Mean & $10.49 \pm 1.10$ & $8.37 \pm 0.96$ & & $6.61 \pm 0.87$ & $1.44 \pm 0.08$ & & $91.93 \pm 0.20$ & $75.17 \pm 3.14$ & \\
\hline \multicolumn{10}{|l|}{ T. tenuifolia } \\
\hline 'Luna Gold' & $20.50 \pm 1.21$ & $16.94 \pm 0.47$ & $-17.4^{*}$ & $13.48 \pm 0.08$ & $6.87 \pm 0.15$ & $-49.0^{* * *}$ & $91.02 \pm 0.27$ & $84.28 \pm 1.80$ & $-7.4^{* *}$ \\
\hline 'Luna Lemon’ & $18.78 \pm 0.50$ & $13.17 \pm 0.35$ & $-29.9^{* * *}$ & $6.07 \pm 0.71$ & $0.51 \pm 0.03$ & $-91.6^{* * *}$ & $90.67 \pm 0.12$ & $39.12 \pm 3.12$ & $-56.9^{* * *}$ \\
\hline 'Luna Orange' & $18.83 \pm 0.97$ & $15.00 \pm 0.38$ & $-20.3^{* *}$ & $7.89 \pm 0.15$ & $0.49 \pm 0.01$ & $-93.8^{* * *}$ & $90.44 \pm 0.44$ & $28.96 \pm 4.02$ & $-68.0^{* * *}$ \\
\hline 'Sarga' & $24.72 \pm 0.88$ & $14.67 \pm 0.58$ & $-40.7^{* * *}$ & $8.65 \pm 0.14$ & $0.61 \pm 0.02$ & $-93.0^{* * *}$ & $91.33 \pm 0.40$ & $74.27 \pm 1.59$ & $-18.7^{* * *}$ \\
\hline Mean & $20.71 \pm 1.40$ & $14.95 \pm 0.78$ & & $9.02 \pm 1.58$ & $2.12 \pm 1.58$ & - & $90.87 \pm 0.19$ & $56.66 \pm 13.38$ & \\
\hline \multicolumn{10}{|l|}{ T. erecta } \\
\hline 'Alacsony Citromsarga' & $8.67 \pm 0.68$ & $5.44 \pm 0.37$ & $-37.3^{* * *}$ & $4.12 \pm 0.01$ & $2.31 \pm 0.09$ & $-43.9^{* * *}$ & $92.13 \pm 0.74$ & $80.84 \pm 3.38$ & $-12.3^{*}$ \\
\hline 'Aranysarga' & $17.61 \pm 0.53$ & $11.44 \pm 0.64$ & $-35.0^{* * *}$ & $7.30 \pm 0.74$ & $5.25 \pm 0.42$ & $-28.1^{\text {n.s. }}$ & $94.22 \pm 0.69$ & $77.78 \pm 3.64$ & $-17.4^{* *}$ \\
\hline 'Cupid Golden Yellow’ & $6.50 \pm 0.40$ & $5.50 \pm 0.29$ & $-15.4^{\text {n.s. }}$ & $2.56 \pm 0.21$ & $2.23 \pm 0.21$ & $-12.9^{\text {n.s. }}$ & $91.54 \pm 0.34$ & $67.27 \pm 2.53$ & $-26.5^{* * *}$ \\
\hline Mean & $10.93 \pm 3.40$ & $7.46 \pm 1.99$ & & $4.66 \pm 1.40$ & $3.26 \pm 0.99$ & & $92.63 \pm 0.81$ & $75.3 \pm 4.11$ & \\
\hline
\end{tabular}

$261{ }^{* * * *},{ }^{* *}, *$, n.s. indicates differences between control and drought stressed plants of the same cultivar, which are significant at $P=0.001$,

$2620.01,0.05$, or non-significant, respectively (Student $t$-test). 


\section{3.2. Photosynthetic pigments}

265

266

On average, total chlorophylls content was higher in T. patula than in the two other species, while the highest average level of carotenoids was observed in T. erecta (Table 2). Yet 268 important differences were found among cultivars of each single species. In the three analysed 269 taxa, total chlorophylls and carotenoid concentrations decreased significantly, in all cultivars except T. patula cv. 'Bolero', which maintained the same levels in stressed plants as those 27 recorded in the control (Table 2). All other cultivars of T. patula showed a 50-70\% reduction of

272 photosynthetic pigments. In T. tenuifolia, 'Luna Gold' showed the smallest reduction and 'Luna 273 Lemon' the highest for both types of pigments. In T. erecta, degradation of chlorophylls was 274 similar in the three cultivars, but the decrease of total carotenoid contents was considerably 275 smaller in 'Alacsony Citromsarga' than in the other two cultivars. 
278 Tab. 2 Total chlorophylls and total carotenoids values (mean $\pm \mathrm{SE}$ ) for control and drought 279 stressed (three weeks without watering) plants of 12 cultivars of three species of Tagetes, and 280 percentage of change of the drought stress treatment over the control.

\begin{tabular}{lcccccc}
\hline \multirow{2}{*}{ Cultivar } & \multicolumn{5}{c}{ Total chlorophylls $\left(\mathrm{mg} \mathrm{g}^{-1} \mathrm{DW}\right)(\mathrm{n}=4)$} & \multicolumn{2}{c}{ Total carotenoids $\left(\mathrm{mg} \cdot \mathrm{g}^{-1} \mathrm{DW}\right)(\mathrm{n}=4)$} \\
\cline { 2 - 7 } T. patula & Control & DS & Change $(\%)^{\mathrm{a}}$ & Control & DS & Change $(\%)^{\mathrm{a}}$ \\
'Bolero' & & & & & & \\
'Orange Flame' & $11.44 \pm 0.80$ & $11.52 \pm 0.75$ & $0.7^{\mathrm{n} . s .}$ & $1.26 \pm 0.11$ & $1.19 \pm 0.13$ & $-5.6^{\text {n.s. }}$ \\
'Orion' & $13.87 \pm 1.43$ & $4.89 \pm 0.15$ & $-64.8^{* * *}$ & $1.64 \pm 0.08$ & $0.79 \pm 0.06$ & $-52.0^{* * *}$ \\
'Robuszta' & $15.71 \pm 0.70$ & $3.44 \pm 0.23$ & $-78.1^{* * *}$ & $1.44 \pm 0.07$ & $0.41 \pm 0.02$ & $-71.9^{* * *}$ \\
'Szinkeverek' & $15.35 \pm 1.56$ & $3.52 \pm 0.44$ & $-77.1^{* * *}$ & $1.51 \pm 0.09$ & $0.68 \pm 0.06$ & $-54.9^{* * *}$ \\
Mean & $12.04 \pm 0.87$ & $4.48 \pm 0.42$ & $-62.8^{* * *}$ & $1.65 \pm 0.11$ & $0.51 \pm 0.03$ & $-69.1^{* * *}$ \\
T. tenuifolia & $13.68 \pm 0.86$ & $5.57 \pm 1.52$ & & $1.50 \pm 0.07$ & $0.71 \pm 0.14$ & \\
'Luna Gold' & & & & & & \\
'Luna Lemon' & $9.69 \pm 0.09$ & $6.33 \pm 0.43$ & $-34.6^{* * *}$ & $1.39 \pm 0.04$ & $0.95 \pm 0.05$ & $-31.7^{* * *}$ \\
'Luna Orange' & $8.78 \pm 0.48$ & $1.65 \pm 0.20$ & $-81.2^{* * *}$ & $1.37 \pm 0.07$ & $0.25 \pm 0.03$ & $-81.8^{* * *}$ \\
'Sarga' & $11.89 \pm 1.46$ & $2.98 \pm 0.12$ & $-74.9^{* * *}$ & $1.50 \pm 0.07$ & $0.39 \pm 0.03$ & $-73.7^{* * *}$ \\
Mean & $11.57 \pm 0.89$ & $5.51 \pm 0.38$ & $-52.4^{* * *}$ & $1.60 \pm 0.07$ & $0.80 \pm 0.08$ & $-49.7^{* * *}$ \\
T. erecta & $10.48 \pm 0.75$ & $4.12 \pm 1.09$ & & $1.46 \pm 0.05$ & $0.60 \pm 0.17$ & \\
'Alacsony Citromsarga' & $13.13 \pm 0.62$ & $4.45 \pm 0.56$ & $-66.1^{* * *}$ & $1.99 \pm 0.12$ & $1.40 \pm 0.11$ & $-29.9^{*}$ \\
'Aranysarga' & $9.24 \pm 0.10$ & $3.22 \pm 0.48$ & $-65.1^{* * *}$ & $2.28 \pm 0.13$ & $0.95 \pm 0.08$ & $-58.2^{* * *}$ \\
'Cupid Golden Yellow' & $9.26 \pm 0.57$ & $4.02 \pm 0.42$ & $-56.6^{* * *}$ & $2.11 \pm 0.18$ & $0.79 \pm 0.08$ & $-62.5^{* * *}$ \\
Mean & $10.54 \pm 1.29$ & $3.90 \pm 0.36$ & & $2.13 \pm 0.08$ & $1.04 \pm 0.18$ & \\
\hline
\end{tabular}

281 a $^{* * *},{ }^{* *},{ }^{*}$, n.s. indicates differences between control and drought stressed plants of the same 282 cultivar, which are significant at $P=0.001,0.01,0.05$, or non-significant, respectively (Student $t$ 283 test). 


\section{3.3. Osmolyte accumulation}

285

286

28

288

289

290

291

292

293

294

295

296

297

298

299

300
Proline (Pro) levels in control plants were highest in T. tenuifolia, intermediate in $T$.

patula and lowest in T. erecta (Table 3). Water stress led to an increase in Pro concentrations in all cultivars, reaching 50-70 fold in T. patula, except for cv. 'Bolero', which experienced a smaller increase, below 10-fold over the non-stressed control. In T. tenuifolia, a strong variation among cultivars, between 3 and 40-fold, was detected (Table 3). Also, in T. erecta cultivars, Pro levels in plants subjected to drought increased from approximately 40-fold in 'Alacsony Citromsarga' to almost 150-fold in 'Cupid Golden Yellow'.

For glycine betaine (GB), the highest levels were observed in T. tenuifolia, both in control and stressed plants, and increased in the three species in response to water stress, from three to six-fold. However, the absolute contents of GB were much lower than those calculated for Pro in the same treated plants (Table 3). Total soluble sugar (TSS) concentrations were highest in T. patula, on average. Under drought conditions, an increase in TSS content of 1.5 to 2.5-fold in relation to the corresponding controls, was detected in T. patula and T. tenuifolia cultivars, and somewhat lower in the T. erecta plants (Table 3 ). 
301 Tab. 3 Proline, fresh weight (FW), glycine betaine (GB) and total soluble sugars (TS) values (mean \pm SE) for control and drought 302 stressed (DS; three weeks without watering) plants of 12 cultivars of three species of Tagetes, and percentage of change of the drought 303 stress treatment over the control.

\begin{tabular}{|c|c|c|c|c|c|c|c|c|c|}
\hline \multirow[b]{2}{*}{ Cultivar } & \multicolumn{3}{|c|}{ Proline $\left(\mu \mathrm{mol} \cdot \mathrm{g}^{-1} \mathrm{DW}\right)(\mathrm{n}=4)$} & \multicolumn{3}{|c|}{$\mathrm{GB}\left(\mu \mathrm{mol} \cdot \mathrm{g}^{-1} \mathrm{DW}\right)(\mathrm{n}=4)$} & \multicolumn{3}{|c|}{ TSS (mg eq. glucose $\left.\mathrm{g}^{-1} \mathrm{DW}\right)(\mathrm{n}=4)$} \\
\hline & Control & DS & Change (\%) & Control & DS & Change (\%) & Control & DS & Change (\%) \\
\hline \multicolumn{10}{|l|}{ T. patula } \\
\hline 'Bolero’' & $6.86 \pm 1.03$ & $67.34 \pm 8.41$ & $881.7^{* * *}$ & $2.15 \pm 0.22$ & $9.10 \pm 0.15$ & $323.9^{* * *}$ & $21.13 \pm 1.62$ & $49.53 \pm 5.49$ & $134.4^{* *}$ \\
\hline 'Orange Flame’ & $5.31 \pm 0.99$ & $250.35 \pm 24.35$ & $4610.8^{* * *}$ & $2.40 \pm 0.07$ & $11.00 \pm 0.76$ & $358.3^{* * *}$ & $24.83 \pm 1.90$ & $36.51 \pm 3.70$ & $47.0^{*}$ \\
\hline 'Orion' & $3.88 \pm 0.88$ & $261.49 \pm 28.72$ & $6635.0^{* * *}$ & $3.08 \pm 0.22$ & $11.40 \pm 0.89$ & $269.8^{* * *}$ & $24.52 \pm 3.80$ & $36.00 \pm 1.62$ & $46.8^{*}$ \\
\hline 'Robuszta' & $4.48 \pm 0.87$ & $275.76 \pm 22.68$ & $6053.2^{* * *}$ & $2.33 \pm 0.17$ & $6.09 \pm 0.31$ & $161.4^{* * *}$ & $27.52 \pm 4.29$ & $35.79 \pm 2.47$ & $30.1^{\text {n.s. }}$ \\
\hline 'Szinkeverek' & $6.17 \pm 0.70$ & $363.32 \pm 11.59$ & $5784.7^{* * *}$ & $1.51 \pm 0.18$ & $7.99 \pm 0.52$ & $427.9^{* * *}$ & $15.64 \pm 1.82$ & $29.36 \pm 1.68$ & $87.7^{* *}$ \\
\hline Mean & $5.34 \pm 0.54$ & $243.65 \pm 48.51$ & & $2.29 \pm 0.25$ & $9.11 \pm 0.98$ & & $22.73 \pm 2.05$ & $37.44 \pm 3.30$ & \\
\hline \multicolumn{10}{|l|}{ T. tenuifolia } \\
\hline 'Luna Gold' & $15.61 \pm 1.55$ & $45.14 \pm 0.56$ & $189.2^{* * *}$ & $7.07 \pm 0.32$ & $12.83 \pm 0.95$ & 81.4 & $9.79 \pm 1.16$ & $24.50 \pm 2.80$ & $150.3^{* *}$ \\
\hline ‘Luna Lemon’ & $7.23 \pm 0.76$ & $230.75 \pm 23.99$ & $3090.3^{* * *}$ & $3.21 \pm 0.21$ & $19.56 \pm 2.07$ & $508.9^{* * *}$ & $16.54 \pm 1.68$ & $24.44 \pm 2.43$ & $47.8^{*}$ \\
\hline 'Luna Orange' & $6.21 \pm 0.08$ & $244.63 \pm 19.06$ & $3836.6^{* * *}$ & $4.92 \pm 0.57$ & $15.23 \pm 1.18$ & $209.6^{* * *}$ & $17.96 \pm 0.71$ & $29.89 \pm 3.47$ & $66.5^{*}$ \\
\hline 'Sarga' & $8.37 \pm 0.50$ & $88.08 \pm 3.92$ & $952.9^{* * *}$ & $3.42 \pm 0.14$ & $14.81 \pm 0.45$ & $332.5^{* * *}$ & $18.23 \pm 1.51$ & $27.76 \pm 0.99$ & $52.3^{* *}$ \\
\hline Mean & $9.36 \pm 2.13$ & $152.15 \pm 50.24$ & & $4.66 \pm 0.89$ & $15.60 \pm 1.42$ & & $15.63 \pm 1.98$ & $26.65 \pm 1.33$ & \\
\hline \multicolumn{10}{|l|}{ T. erecta } \\
\hline 'Alacsony Citromsarga' & $2.48 \pm 0.18$ & $97.05 \pm 3.65$ & $3819.2^{* * *}$ & $3.28 \pm 0.14$ & $15.86 \pm 0.84$ & $383.9^{* * *}$ & $13.69 \pm 0.90$ & $16.83 \pm 1.29$ & $23.0^{\text {n.s. }}$ \\
\hline 'Aranysarga' & $2.77 \pm 0.24$ & $248.06 \pm 3.46$ & $8867.7^{* * *}$ & $2.80 \pm 0.32$ & $7.40 \pm 0.42$ & $163.8^{* * *}$ & $19.82 \pm 0.90$ & $22.65 \pm 1.31$ & $14.3^{\text {n.s. }}$ \\
\hline 'Cupid Golden Yellow' & $2.30 \pm 0.19$ & $343.45 \pm 20.32$ & $14810.8^{* * *}$ & $3.57 \pm 0.35$ & $11.40 \pm 0.67$ & $219.4^{* * *}$ & $11.73 \pm 0.91$ & $16.02 \pm 1.95$ & $36.5^{\text {n.s. }}$ \\
\hline Mean & $2.52 \pm 0.14$ & $229.52 \pm 71.82$ & & $3.22 \pm 0.22$ & $11.55 \pm 2.45$ & & $15.08 \pm 2.44$ & $18.50 \pm 2.09$ & \\
\hline
\end{tabular}

$304{ }^{* * *},{ }^{* *},{ }^{*}$, n.s. indicates differences between control and drought stressed plants of the same cultivar, which are significant at $305 P=0.001,0.01,0.05$, or non-significant, respectively (Student $t$-test). 
307 3.4. Malondialdehyde and non-enzymatic antioxidants

308

309 Average malondialdehyde (MDA) levels were higher in T. tenuifolia and T. erecta than in

310 T. patula and increased slightly in the stressed plants of most Tagetes cultivars under study 311 (Table 4). However, for one cultivar of T. patula ('Bolero') and all cultivars of T. tenuifolia 312 except 'Sarga', the differences were not significant (Table 4). Total phenolic compounds (TPC)

313 and total flavonoids (TF) were higher in T. patula and T. tenuifolia than in T. erecta and 314 increased in stressed plants of the three species, but again this increment was generally low (1.06 315 to 1.65 -fold for TPC and 1.02 to 1.51 -fold for TF), and it was not significant in several of the 316 cultivars under study (Table 4). 
318 Tab. 4 Malondialdehyde (MDA), total phenolic compounds (TPC), and total flavonoids (TF) values (mean \pm SE) for control and 319 drought stressed (DS; three weeks without watering) plants of 12 cultivars of three species of Tagetes, and percentage of change of the 320 drought stress treatment over the control.

\begin{tabular}{|c|c|c|c|c|c|c|c|c|c|}
\hline \multirow[b]{2}{*}{ Cultivar } & \multicolumn{3}{|c|}{ MDA $\left(n m o l \cdot g^{-1}\right.$ DW) $(n=4)$} & \multicolumn{3}{|c|}{ TPC (mg eq. GA $\left.\cdot \mathrm{g}^{-1} \mathrm{DW}\right)(\mathrm{n}=4)$} & \multicolumn{3}{|c|}{ TF (mg eq. $\left.C \cdot g^{-1} D W\right)(n=4)$} \\
\hline & Control & $\mathrm{DS}$ & Change (\%) & Control & DS & Change (\%) & Control & DS & Change (\%) \\
\hline \multicolumn{10}{|l|}{ T.patula } \\
\hline ‘Bolero’ & $282.43 \pm 46.09$ & $279.47 \pm 23.86$ & $-1.0^{\text {n.s. }}$ & $5.47 \pm 0.92$ & $6.53 \pm 0.93$ & $19.4^{\text {n.s. }}$ & $6.84 \pm 0.34$ & $7.13 \pm 0.74$ & $4.2^{\text {n.s. }}$ \\
\hline 'Orange Flame' & $312.10 \pm 4.91$ & $350.91 \pm 53.06$ & $12.4^{\text {n.s. }}$ & $7.16 \pm 1.03$ & $8.57 \pm 0.79$ & $19.7^{\text {n.s. }}$ & $6.83 \pm 0.14$ & $8.34 \pm 0.33$ & $22.1^{* *}$ \\
\hline ‘Orion’ & $254.22 \pm 26.93$ & $351.07 \pm 4.51$ & $38.1^{*}$ & $7.25 \pm 1.18$ & $8.46 \pm 0.82$ & $16.6^{\text {n.s. }}$ & $7.21 \pm 0.62$ & $9.29 \pm 0.43$ & $28.8^{*}$ \\
\hline 'Robuszta' & $216.18 \pm 7.50$ & $307.06 \pm 9.34$ & $42.0^{* * *}$ & $4.63 \pm 0.23$ & $7.68 \pm 0.27$ & $65.8^{* * *}$ & $6.74 \pm 0.35$ & $9.05 \pm 0.34$ & $34.2^{*}$ \\
\hline 'Szinkeverek' & $365.39 \pm 36.77$ & $388.06 \pm 29.07$ & $6.2^{\text {n.s. }}$ & $6.27 \pm 0.12$ & $7.20 \pm 0.50$ & $14.9^{\text {n.s. }}$ & $7.88 \pm 0.28$ & $8.66 \pm 0.50$ & $9.9^{\text {n.s. }}$ \\
\hline Mean & $286.06 \pm 25.45$ & $335.31 \pm 19.01$ & & $6.16 \pm 0.50$ & $7.69 \pm 0.38$ & & $7.10 \pm 0.21$ & $8.49 \pm 0.38$ & \\
\hline \multicolumn{10}{|l|}{ T. tenuifolia } \\
\hline 'Luna Gold' & $431.65 \pm 5.09$ & $437.98 \pm 29.87$ & $1.5^{\text {n.s. }}$ & $7.13 \pm 0.82$ & $8.22 \pm 0.13$ & $15.2^{\text {n.s. }}$ & $4.68 \pm 0.42$ & $4.79 \pm 0.60$ & $2.3^{\text {n.s. }}$ \\
\hline 'Luna Lemon’ & $428.71 \pm 30.84$ & $431.50 \pm 16.13$ & $0.6^{\text {n.s. }}$ & $6.51 \pm 1.15$ & $7.06 \pm 0.33$ & $8.5^{\text {n.s. }}$ & $5.20 \pm 0.59$ & $7.85 \pm 0.59$ & $51.0^{*}$ \\
\hline 'Luna Orange' & $432.29 \pm 26.65$ & $451.17 \pm 18.37$ & $4.4^{\text {n.s. }}$ & $8.38 \pm 0.35$ & $10.03 \pm 0.79$ & $19.7^{\text {n.s. }}$ & $5.52 \pm 0.38$ & $7.70 \pm 0.80$ & $39.5^{*}$ \\
\hline 'Sarga' & $512.34 \pm 39.56$ & $639.19 \pm 16.53$ & $24.8^{*}$ & $6.87 \pm 0.51$ & $7.34 \pm 0.23$ & $6.8^{\text {n.s. }}$ & $4.83 \pm 0.23$ & $7.31 \pm 0.92$ & $51.5^{*}$ \\
\hline Mean & $451.25 \pm 20.38$ & $489.96 \pm 49.91$ & & $7.22 \pm 0.41$ & $8.16 \pm 0.67$ & & $5.06 \pm 0.19$ & $6.91 \pm 0.72$ & \\
\hline \multicolumn{10}{|l|}{ T. erecta } \\
\hline 'Alacsony Citromsarga' & $414.50 \pm 50.48$ & $440.35 \pm 22.40$ & $6.2^{\text {n.s. }}$ & $4.13 \pm 0.37$ & $4.40 \pm 0.39$ & $6.7^{\text {n.s. }}$ & $2.99 \pm 0.26$ & $3.21 \pm 0.14$ & $7.6^{\text {n.s. }}$ \\
\hline ‘Aranysarga' & $451.88 \pm 26.47$ & $559.07 \pm 17.20$ & $23.7^{*}$ & $3.91 \pm 0.33$ & $4.13 \pm 0.09$ & $5.5^{\text {n.s. }}$ & $2.72 \pm 0.19$ & $3.27 \pm 0.09$ & $20.3^{*}$ \\
\hline 'Cupid Golden Yellow’ & $408.89 \pm 38.79$ & $574.18 \pm 58.67$ & $40.4^{\text {n.s. }}$ & $2.52 \pm 0.25$ & $3.14 \pm 0.31$ & $24.6^{\text {n.s. }}$ & $2.83 \pm 0.31$ & $3.00 \pm 0.16$ & $6.0^{\text {n.s. }}$ \\
\hline Mean & $425.09 \pm 13.51$ & $524.53 \pm 42.37$ & & $3.52 \pm 0.50$ & $3.90 \pm 0.38$ & & $2.85 \pm 0.08$ & $3.16 \pm 0.08$ & \\
\hline
\end{tabular}

$321{ }^{* * *},{ }^{* *},{ }^{*}$, n.s. indicates differences between control and drought stressed plants of the same cultivar, which are significant at $P=0.001$, $3220.01,0.05$, or non-significant, respectively (Student $t$-test). 


\section{3.5. Multivariate analysis}

325

326

327 respectively, of the total variation observed. The first component displayed a strong positive correlation with plant growth traits: fresh weight and water content, as well as with photosynthetic pigments, while it showed a negative correlation with osmolytes and the analyzed antioxidants (Fig. 1). The second principal component was highly correlated with total

331 chlorophylls, total soluble sugars and antioxidants, and negatively correlated with the oxidative 332 stress marker MDA.

The PCA plot with the mean values of cultivars tested under control and drought stress 334 conditions clearly separates the control materials, which have positive values for this first component, from the materials subjected to drought stress (Fig. 2). The cultivars that under the 336 drought stress treatment had higher values (i.e., closer to non-stressed controls) were 'Bolero' for 337 T. patula, 'Luna Gold' for T. tenuifolia and the three cultivars of T. erecta. Furthermore, within 338 T. patula and T. tenuifolia, a large dispersion is observed among the cultivars subjected to stress 339 in this first component (Fig. 2). The second component separates the three species, with $T$. patula 340 displaying higher values, $T$. tenuifolia intermediate ones and T. erecta the lowest values. 


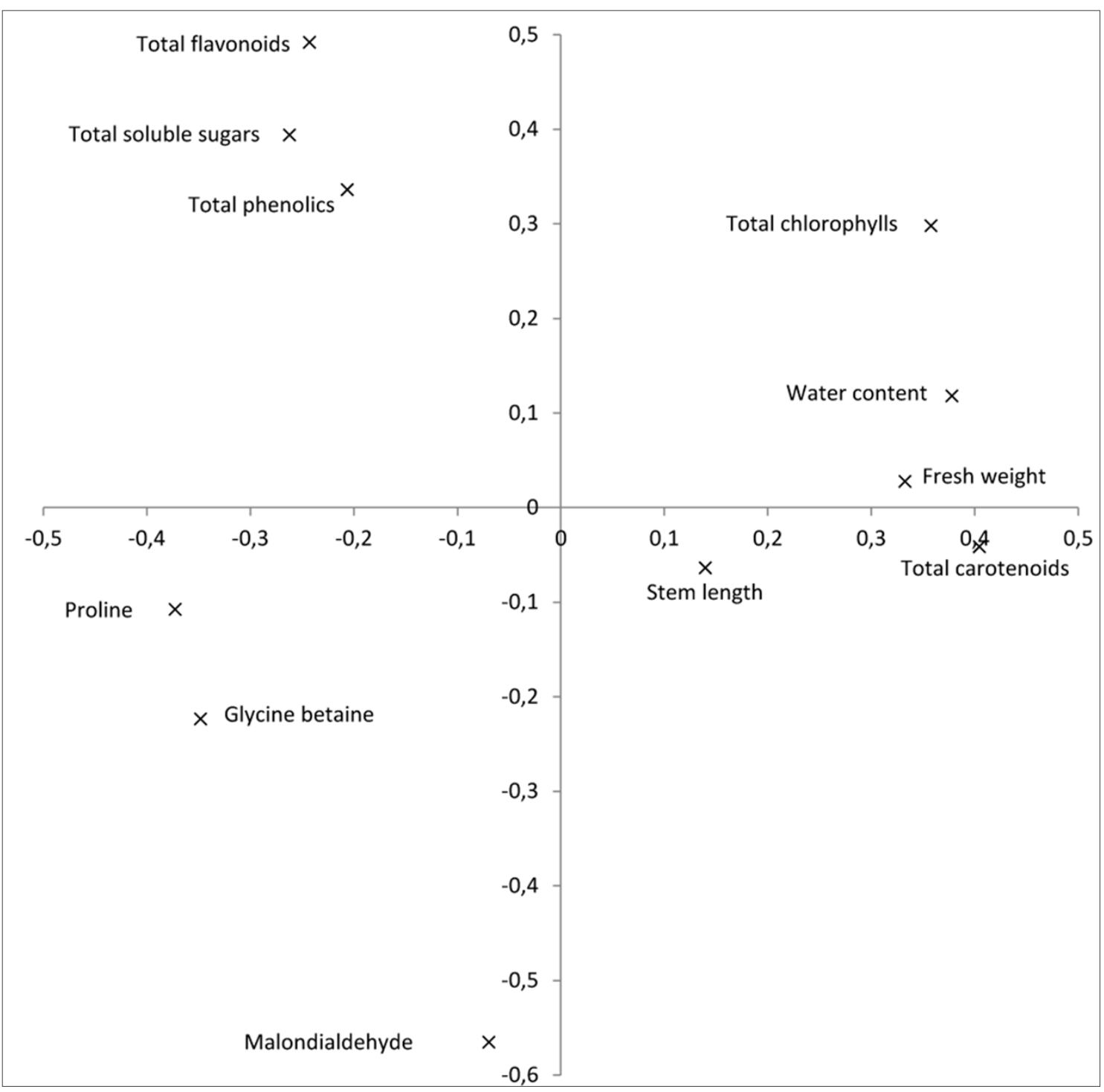

343

Fig. 1 Relationships between the plant growth (stem length, fresh weight, and water content), photosynthetic pigments (total chlorophylls, total carotenoids), soluble solutes (proline, glycine betaine, and total soluble solutes), oxidative stress marker MDA and to anti-oxidants (total phenolics and total flavonoids) based on the two first components of the principal components analysis (accounting for $48.7 \%$ and $20.9 \%$ of the total variation, respectively). 


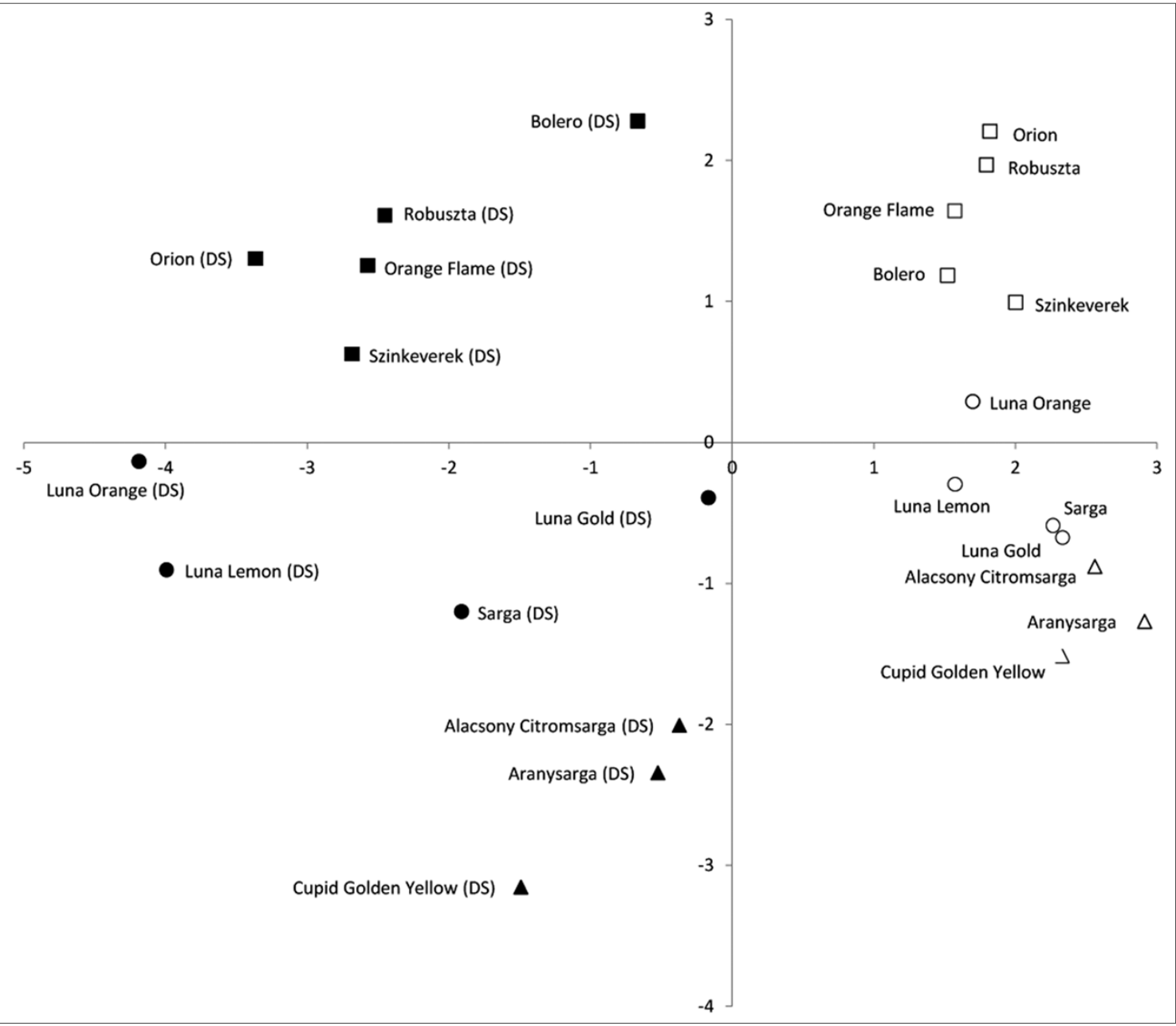

350

Fig. 2 Similarities based on plant growth and biochemical marker traits among controls and 352 drought stressed materials of 12 varieties of three Tagetes species (T. patula, T. tenuifolia and T. erecta) based on the two first components of the principal components analysis (accounting for

$35448.7 \%$ and $20.9 \%$ of the total variation, respectively). Control and drought stressed materials are 355 represented by white and black symbols, respectively. Additionally "(DS)" is indicated in the 356 drought stressed materials. Cultivars of $T$. patula are represented by squares, those of $T$. 357 tenuifolia by circles and those of $T$. erecta by triangles).

\section{Discussion}

Plant water relations are strongly affected by water deficit, as drought has a direct effect on photosynthesis and growth rate (Chaves and Oliveira, 2004). Severe drought reduces the rate of cell division and cell enlargement, affects enzyme activities, causes loss of turgor and a drop 
364 in the synthesis of carbohydrates through photosynthesis (Farooq et al., 2012 and references 365 within). Reduction of growth under drought stress conditions is more pronounced in stress 366 sensitive plants than in the stress tolerant ones (Demiral and Türkan, 2005) and, in consequence,

367 the selection of cultivars tolerant to drought is needed when drought stress is expected. This has 368 a particular importance in the Mediterranean region, characterized by harsh climatic conditions 369 in summer, which probably will worsen in the near future due to the global warming (Rubio, 370 2009).

Among herbaceous ornamentals, the species of the genus Tagetes are considered as 372 relatively drought resistant, as they are native to areas with hot and dry climate (Henson et al., 373 2006). However, the results obtained here indicate that there is a large variation among marigold 374 species regarding their ability to respond to severe water stress. According to different evaluated 375 parameters, related to tolerance to drought, the most tolerant of the three species proved to be $T$. 376 erecta. When considering cultivars within species, T. patula and T. tenuifolia, lost more than 377 double of their FW under stress, in comparison to T. erecta. This confirms previous findings that 378 reported this species as drought tolerant (Henson et al., 2006; Riaz et al., 2013), and even as able 379 to withstand moderate salinity (Valdez-Aguilar et al., 2009, Sayyed et al., 2014). The most 380 affected by stress were cultivars of signet marigold (T. tenuifolia), and T. patula was in an 381 intermediate position, although both species have been considered as tolerant to short-time 382 drought (Borch et al., 2003; Kafi and Jouyban, 2013). When comparing the stem length, signet 383 marigold cultivars had considerably longer stems than the others in both control and drought 384 stress treatments. The rate of growth, implicitly the size of plants, is directly related to the effect 385 of water stress.

386 Besides interspecific differences, drought tolerance largely varies among genotypes 387 within crop species (Gholami et al., 2012; Cortés et al. 2012; Siddiqui et al. 2015, Yang et al. 388 2015). Also, it is known that seedlings or young plants are generally more affected by stress than 389 plants at later developmental stages (Vicente et al., 2004). Therefore, selection in early stages may be an efficient way to select drought tolerant cultivars of Tagetes.

391 Cultivars 'Szinkeverek', 'Robuszta', and 'Bolero' of T. patula showed a smaller stress392 induced reduction of SL and FW, but the latter also appeared to be more resistant to dehydration, 393 since water loss under drought conditions was relatively lower. Therefore, we assume that cv.

394 'Bolero' is the most appropriate for cultivation in areas or conditions where drought may occur 
395 frequently. In the species T. tenuifolia, the genotype 'Luna Gold' was clearly the most drought 396 tolerant of the four cultivars analyzed here. Among the cultivars of T. erecta, the smallest 397 reduction in LS and FW was registered in 'Cupid Golden Yellow', although it showed a more 398 pronounced reduction in its WC than the other cultivars.

Although growth parameters are reliable and commonly used to assess the effects of stress in most plant species, they can be complemented or even substituted by suitable biochemical markers, which include a large array of compounds that can be easily and quickly identified (Schiop et al., 2015). In addition, the measurement of these biochemical markers can be made without the destruction of the plant required for measuring some growth traits, such as fresh weight. Abiotic stresses, including drought, lead the degradation of photosynthetic pigments (Parida and Das, 2005). Monitoring the decrease in the contents of photosynthetic pigments in affected plants can be used as a biomarker of stress (Schiop et al., 2015), There are numerous reports of decreased levels of chlorophylls and carotenoids under water stress in different species (i.e., Logini et al., 1999; Agastian et al., 2000; Al Hassan et al., 2015; Yang et al. 2015), including T. erecta (Riaz et al., 2013), thus our findings confirm that in the Tagetes species evaluated, the reduction in the levels of photosynthetic pigments matches the inhibition of growth in the different cultivars.

Osmotic stress induces cellular accumulation of compatible solutes, or osmolytes in all

413 plants, regardless of them being tolerant or not to abiotic stress (Ashraf and Foolad, 2007). One 414 ubiquitous osmolyte in plants is proline, which is synthesised under many different 415 environmental stress conditions, such as salinity, drought, cold, high temperature, nutritional 416 deficiencies, heavy metals, air pollution or high UV radiation (Hare et al., 1998; Grigore et al., 417 2011). In addition to its role in osmotic adjustment, Pro plays many other functions, as 418 'osmoprotectant', directly stabilising proteins, membranes and other subcellular structures, 419 scavenging free radicals, or balancing the cell redox status under stress conditions (Smirnoff and 420 Cumbes, 1989; Verbruggen and Hermans, 2008), as well as contributing to storage of carbon and 421 nitrogen during stress, which will help cell and tissue recovery when stress eases or disappears 422 (Szabados and Savouré, 2010). Studies on congeneric wild species or on different cultivars of the 423 same species, highlight that although higher Pro levels can be found in the more tolerant taxa 424 (Boscaiu et al., 2013; Ghanbari et al., 2013), there is often no positive correlation between Pro 425 contents and the relative degree of tolerance (Ashraf and Foolad, 2007; Chen et al., 2007). In all 
426 cultivars analysed here there was a significant increase in Pro, some reaching very high levels, as 427 reported previously in other Tagetes cultivars (Mohamed et al., 2000). The concentrations that 428 we measured indicate that Pro plays an important role in osmotic adjustment in Tagetes. 429 However, there is only a slight correlation of Pro levels and the reduction of the water content of 430 plants under drought, and not statistically significant. In the French marigold, WC did not change 431 significantly in cv. 'Bolero' and a much smaller increase was registered in Pro levels in 432 comparison with the other cultivars of this species. In signet marigold, the two cultivars that had 433 a higher water loss ('Luna Orange' and 'Luna Lemon') accumulated much higher amounts of 434 Pro, and in the African marigold, the highest level of Pro was registered in 'Cupid Golden 435 Yellow', which reduced more its WC under drought than the two other cultivars.

Glycine betaine (GB) is a quaternary ammonium compound synthesised in response to salt and water stress in many different plant groups (Hanson and Scott; 1980; Rhodes and 438 Hanson, 1993; Ashraf and Foolad, 2007). There are no previous reports on the levels and role of this osmolyte in marigold, but we found that it increases significantly under drought in all genotypes. However, the values that we detected are by far much lower than those found in plants that are true GB accumulators (Khan et al., 2000; Gil et al., 2013). Carbohydrates also play an important role as osmolytes in many plants species (Gil et al., 2011); in Tagetes, total soluble sugars contents increased in response to drought, in all tested cultivars.

Malondialdehyde (MDA) is a product of membrane lipid peroxidation, considered a reliable general marker of oxidative stress (Del Rio et al., 2005), and it is routinely used to assess the degree of oxidative damage induced in plants by different stress treatments. In comparative analyses, more tolerant cultivars generally exhibit a smaller amount of MDA, as reported in many species (e.g., Hussain et al., 2013). In the present study, MDA increase was not significant in all cultivars and its levels could not be correlated with the degree of tolerance. On the other hand, phenolic compounds and especially a subgroup of them, the flavonoids, are plant secondary metabolites which are important in the mechanisms of adaptation to abiotic stresses 452 (Di Ferdinando et al. 2012, 2014), among many other biological functions. Since many 453 flavonoids and other phenolic compounds are strong antioxidants, their accumulation in plants 454 can reduce the oxidative damage induced by different abiotic stresses, including drought 455 (Bautista et al., 2016). Flavonoids are regarded as a secondary ROS scavenging system activated 456 in plants under severe stress because of the depletion of primary antioxidant defence systems. 
457 Therefore, the biosynthesis of antioxidant flavonoids is triggered, especially under severe stress 458 conditions, when the activities of antioxidant enzymes, considered the first line of defence 459 against ROS, decline (Fini et al., 2011). Cultivars of the species T. erecta are known for their 460 high phenolic and flavonoid contents and radical-scavenging activity (Li et al., 2007). Water 461 stress induced a significant increase in the levels of total phenolic compounds and total 462 flavonoids in all genotypes. Total antioxidant flavonoids generally correlated better than total 463 phenolics with the morphological markers of stress.

464 The combined analysis through a PCA of the different parameters evaluated allowed a 465 clear identification of the most tolerant cultivars in each species, which are those that plot closer 466 to the non-stressed materials, as well as those traits that present a greater association with 467 drought tolerance. This approach, based on traits measured in young plants, may allow the early 468 identification of drought stress tolerant cultivars of Tagetes.

469

470

\section{Conclusions}

471

472

We have identified several tolerant cultivars to drought in three ornamental Tagetes species. The large variation observed among species and among cultivars within species indicates that there are good prospects for the selection of cultivars with enhanced tolerance to drought. The degradation of photosynthetic pigments and changes in the levels of osmolytes, total phenolics and total flavonoids are suitable markers for testing the tolerance to drought in Tagetes cultivars. Among the osmolytes, the most reliable stress marker is proline: higher levels of Pro were detected in the more sensitive genotypes of the same species - and, therefore, those more affected by drought. As a response to oxidative stress, an increase in total phenolic compounds and total flavonoids was detected, generally lower in the more tolerant cultivars. Our study revealed that, when comparing different species belonging to the same genus, it is more appropriate the simultaneous use of several biochemical markers, as this allows the identification of tolerant cultivars. Since the amount of plant material required for these biochemical analyses

484 is very low, they can be used in early seedling stages, without the necessity of growing the plants 485 and analysing their growth response, which can be more laborious and time consuming. Our 486 results contribute to the methods of screening for drought tolerance in Tagetes, an important 
487 objective for the production of plants of this ornamental species with improved water efficiency

488 and adapted to a climate change scenario, especially in the Mediterranean region.

489

490

\section{References}

491

492

Adams DW. 2004. Restoring American gardens: An encyclopedia of heirloom ornamental 493 plants, 1640-1940. Portland, USA: Timberpress.

Agastian P, Kingsley SJ, Vivekanandan M. 2000. Effects of salinity on photosynthesis and biochemical characteristics in mulberry genotypes. Photosynthetica 38: 287-290.

Al Hassan M, Fuertes M, Sanchez F, Vicente O, Boscaiu M. 2015. Effects of salt and water stress on plant growth and on accumulation of osmolytes and antioxidant compounds in cherry tomato. Notulae Botanicae Horti Agrobotanici Cluj-Napoca 43:1-11.

Apel K, Hirt H. 2004. Reactive oxygen species: metabolism, oxidative stress, and signal transduction. Annual Review of Plant Physiology 55:373-399.

Ashraf M, Harris PJC. 2004. Potential biochemical indicators of salinity tolerance in plants. Plant Science 166:3-16.

Ashraf M, Foolad MR. 2007. Roles of glycine betaine and proline in improving plant abiotic stress resistance. Environmental Experimental Botany 59:206-216.

Bates LS, Waldren RP, Teare ID. 1973. Rapid determination of free proline for water stress studies. Plant \& Soil 39:205-207.

Bautista I, Boscaiu M, Lidón A, Llinares JV, Lull C, Donat MP, Mayoral O, Vicente O. 2016. Environmentally induced changes in antioxidant phenolic compounds levels in wild plants. Acta Physiologiae Plantarum 38:9. doi 10.1007/s11738-015-2025-2

Bijanzadeh E, Emam Y. 2010. Effect of defoliation and drought stress on yield components and chlorophyll content of wheat. Pakistan Journal of Biological Sciences 13:699-705.

513

514

515

516

517
Blainski A, Lopes GC, Palazzo de Mello JC. 2013. Application and analysis of the Folin Ciocalteu method for the determination of the total phenolic content from Limonium brasiliense L. Molecules 18:6852-6865.

Borch K, Miller C, Brown KM, Lynch J. 2003. Improved drought tolerance in marigold by manipulation of root growth with buffered-phosphorus nutrition. HortScience 38, $212-216$. 
518 Boscaiu M, Lull C, Llinares J, Vicente O, Boira H. 2013. Proline as a biochemical marker in

519

520

521

522

523

524

525

526

527

528

529

530

531

532

533

534

535

536

537

538

539

540

541

542

543

544

545

546

547

548 relation to the ecology of two halophytic Juncus species. Journal of Plant Ecology 6:177-186.

Chaves MM, Oliveira MM. 2004. Mechanisms underlying plant resilience to water deficits: prospects for water-saving agriculture. Journal of Experimental Botany 55:2365-2384.

Chen Z, Cuin TA, Zhou M, Twomei A, Naidu BP, Shabala S. 2007. Compatible solute accumulation and stress-mitigating effects in barley genotypes contrasting in their salt tolerance. Journal of Experimental Botany 58:4245-4255.

Cicevan R, Al Hassan M, Sestras A, Boscaiu M, Zaharia A, Vicente O, Sestras. 2015. Comparative analysis of osmotic and ionic stress effects on seed germination in Tagetes (Asteraceae) cultivars. Propagation of Ornamental Plants 15:63-72.

Cortés AJ, Chavarro C, Madriñán S, This D, Blair MW. 2012. Molecular ecology and selection in the drought-related $A s r$ gene polymorphisms in wild and cultivated common bean (Phaseolus vulgaris L.). BMC Genetics 16:13:58. DOI: 10.1186/1471-2156-13-58.

Del Rio D, Stewart AJ, Pellegrini N. 2005. A review of recent studies on malondialdehyde as toxic molecule and biological marker of oxidative stress. Nutrition, Metabolism and Cardiovascular Diseases 15:316-328.

Demiral T, Türkan I. 2005. Comparative lipid peroxidation, antioxidant defense systems and proline content in roots of two rice cultivars differing in salt tolerance. Environmental and Experimental Botany 53:247-257.

Di Ferdinando M, Brunetti C, Agati G, Tattini M. 2014. Multiple functions of polyphenols in plants inhabiting unfavourable Mediterranean areas. Environmental and Experimental Botany 103:107-116.

Di Ferdinando M, Brunetti C, Fini A, Tattini M. 2012. Flavonoids as antioxidants in plants under abiotic stresses. In: Ahmad P, Prasad MNV, eds. Abiotic stress responses in plants: metabolism productivity and sustainability. New York: Springer Verlag, 159-179.

Dubois M, Gilles KA, Hamilton JK, Reberd PA, Smith F. 1956. Colorimetric method for determination of sugars and related substances. Analytical Chemistry 28: 350-356.

Farooq M, Hussain M, Wahid A, Siddique KHM. 2012. Drought stress in plants: an overview. In: Aroca R, ed. Plant responses to drought stress from morphological to molecular features. Berlin, Heidelberg: Springer Verlag, 1-33. 
549 Fini A, Brunetti C, Di Ferdinando M, Ferrini F, Tattini M. 2011. Stress-induced flavonoid

550

551

552

553

554

555

556

557

558

559

560

561

562

563

564

565

566

567

568

569

570

571

572

573

574

575

576

577 biosynthesis and the antioxidant machinery of plants. Plant Signaling \& Behavior 6:709711.

Ghanbari AA, Mousavi SH, Mousapou Gorji A, Rao I. 2013. Effects of water stress on leaves and seeds of bean (Phaseolus vulgaris L.). Turkish Journal of Field Crops 18:73-77.

Gholami M, Rahemi M, Rastegar S. 2012. Use of rapid screening methods for detecting drought tolerant cultivars of fig (Ficus carica L.). Scientia Horticulturae 143:7-14.

Giannakopoulos C, Le Sager P, Bindi M, Moriondo M, Kostopoulou E, Goodess CM. 2009. Climatic changes and associated impacts in the Mediterranean resulting from a $2{ }^{\circ} \mathrm{C}$ global warming. Global and Planetary Change. DOI: 10.1016/j.gloplacha.2009.06.001.

Gil R, Bautista I, Boscaiu M, Lidón A, Wankhade S, Sánchez H, Llinares J, Vicente O. 2014. Responses of five Mediterranean halophytes to seasonal changes in environmental conditions. AoB Plants. DOI:10.1093/aobpla/plu049.

Gil R, Boscaiu M, Lull C, Bautista I, Lidón A, Vicente O. 2013. Are soluble carbohydrates ecologically relevant for salt tolerance in halophytes? Functional Plant Biology 40:805818.

Gil R, Lull C, Boscaiu M, Bautista I, Lidón A, Vicente O. 2011. Soluble carbohydrates as osmolytes in several halophytes from a Mediterranean salt marsh. Notulae Botanicae Horti Agrobotanici Cluj-Napoca 39:9-17.

Gilman EF, Howe T. 1999. Tagetes erecta. Fact Sheet FPS-569. Gainesville, USA: Institute of Food and Agricultural Science, University of Florida.

Giri RI, Bose A, Mishra SK, 2011. Hepatoprotective activity of Tagetes erecta against carbon tetrachloride-induced hepatic damage in rats. Acta poloniae pharmaceutica 68:999-1003.

Gholinezhad E, Darvishzadeh R, Bernousi I. 2014. Evaluation of drought tolerance indices for selection of confectionery sunflower (Helianthus annuus L.) landraces under various environmental conditions. Notulae Botanicae Horti Agrobotanici Cluj-Napoca 42:187201.

Grieve CM, Grattan SR. 1983. Rapid assay for the determination of water soluble quaternary ammonium compounds. Plant \& Soil 70:303-307. 
578 Grigore MN, Boscaiu M, Vicente O. 2011. Assessment of the relevance of osmolyte biosynthesis

579

580

581

582

583

584

585

586

587

588

589

590

591

592

593

594

595

596

597

598

599

600

601

602

603

604

605

606

for salt tolerance of halophytes under natural conditions. European Journal of Plant Science and Biotechnology 5:12-19.

Halliwell B. 2006. Reactive species and antioxidants. Redox biology is a fundamental theme of aerobic life. Plant Physiology 141:312-322.

Hanson AD, Scott NA. 1980. Betaine synthesis from radioactive precursors in attached, water stressed barley leaves. Plant Physiology 66:342-348.

Hare PD, Cress WA, van Standen J. 1998. Dissecting the roles of osmolyte accumulation during stress. Plant, Cell \& Environment 21:535-553.

Henson DY, Newman SE, Hartley DY. 2006. Performance of selected herbaceous annual ornamentals grown at decreasing levels of irrigation. HortScience 41: 1481-1486.

Hodges DM, DeLong JM, Forney CF, Prange RK. 1999. Improving the thiobarbituric acidreactive-substances assay for estimating lipid peroxidation in plant tissues containing anthocyanin and other interfering compounds. Planta 207:604-611.

Hollis L, Gonzalez AL, Walsh CG. 2012. Biopesticides registration action document. U.S. Environmental Protection Agency: Office of Pesticide Programs Biopesticides and Pollution Prevention Division, p.5.

Hussain MA, Mukhtar T, Kayani MZ. 2011. Combined wound healing activity of Gymnema sylvestre and Tagetes erecta Linn. International Journal of Pharmaceutical Applications 2:135-140.

Hussain I, Ashraf MA, Anwar F, Rasheed R, Niaz M, Wahid A. 2013. Biochemical characterization of maize (Zea mays L.) for salt tolerance. Plant Biosystems 148: 10161026.

IPCC. 2014. Intergovernmental panel on climate change. In: Proceeding of the 5th Assessment Report, WGII, Climate Change 2014: Impacts, Adaptation, and Vulnerability. Cambridge, Cambridge University Press. Available at: http://www.ipcc.ch/report/ar5/wg2/ (accessed on July 13, 20149)

Jothi D. 2008. Extraction of natural dyes from African marigold flower (Tagetes erecta L.) for textile coloration. Autex Research Journal 8:49-53. 
607 Kafi M, Jouyban Z. 2013. Study of effects of different levels of irrigation interval and nitrogen 608 on some physiological traits of signet marigold (Tagetes tenuifolia). Life Science Journal 609 10:348-350.

610 Khan MA, Ungar IA, Showalter AM. 2000. The effect of the salinity on the growth, water status, and ion content of a leaf succulent perennial halophyte, Suaeda fruticosa (L.) Forssk. Journal of Arid Environments 45:73-84.

613 Li W, Gao Y, Zhao J, Wang Q. 2007. Phenolic, flavonoid, and lutein ester content and antioxidant activity of 11 cultivars of Chinese marigold. Journal of Agricultural and Food Chemistry 55:8478-8484.

Lichtenthaler HK, Wellburn AR. 1983. Determinations of total carotenoids and chlorophylls a and $\mathrm{b}$ of leaf extracts in different solvents. Biochemical Society Transactions 11:591-592.

Lokesh JS. 2009. Pharmacological evaluation of ethanolic extract of flowers of Tagetes erecta

624

Logini B, Scartazza A, Brugnoli E, Navari-Izzo F. 1999. Antioxidant defense system, pigment composition, and photosynthetic efficiency in two wheat cultivars subjected to drought. Plant Physiology 119:1091-1099. on epilepsy. Journal of Pharmacy Research 2:1035-1038.

Mafakheri A, Siosemardeh A, Bahramnejad B, Struik PC, Sohrabi Y. 2010. Effect of drought stress on yield, proline and chlorophyll contents in three chickpea cultivars. Australian Journal of Crop Science 4:580-585.

Maity N, Keema NK, Abedy MK, Sarkar BK, Mukherjee PK. 2011. Exploring Tagetes erecta Linn. flower for the elastase, hyaluronidase and MMP-1 inhibitory activity. Journal of Ethnopharmacology 137:1300-1305.

Mantri N, Patade V, Pang E. 2014. Recent advances in rapid and sensitive screening for abiotic stress tolerance. In: Ahmad. P. et al., eds. Improvement of crops in the era of climatic changes vol. 2. New York: Springer Verlag, 37-47.

Mohamed MAH, Harris PJC, Henderson J. 2000. In vitro selection and characterisation of a drought tolerant clone of Tagetes minuta. Plant Science 159:213-222.

Niu G, Rodriguez DS, Wang IT. 2006. Impact of drought and temperature on growth and leaf gas exchange of six bedding plant species under greenhouse conditions. HortScience 41:1408-1411. 
638 Parida AK, Das AB. 2005. Salt tolerance and salinity effects on plants: a review. Ecotoxicology

639

640

641

642

643

644

645

646

647

648

649

650

651

652

653

654

655

656

657

658

659

660

661

662

663

664

665

666

667 and Environmental Safety 60:324-349.

Raghuveer R, Sreeja K, Sanjeeva AK. 2011. Antihyperlipidemic effect of Tagetes erecta in cholesterol fed hyperlipidemic rats. Der Pharmacia Lettre 3:266-270.

Rhodes D, Hanson AD. 1993. Quaternary ammonium and tertiary sulfonium compounds in higher plants. Annual Review of Plant Physiology and Plant Molecular Biology 44:357384.

Riaz A, Younis A, Riaz Taji A, Karim A, Tariq U, Munir S, Riaz S. 2013. Effect of drought stress on growth and flowering of marigold (Tagetes erecta L.). Pakistan Journal of Botany 45(S1):123-131.

Rubio JL. 2009. Desertification and water scarcity as a security challenge in the Mediterranean. In: Rubio JL, Safriel U, Daussa R, Blum W, Pedrazzini F, eds. Water scarcity, land degradation and desertification in the Mediterranean Region. Berlin Heidelberg: Springer Verlag, 75-92.

Ruddock PS, Charland M, Ramirez S, Lopez A, Towers NGH, Arnason JT, Liao M, Dillon J. 2011. Antimicrobial activity of flavonoids from Piper lanceaefolium and other Colombian medicinal plants against antibiotic susceptible and resistant strains of Neisseria gonorrhoeae. Sexually Transmitted Diseases 38:81-88.

Sayyed A, Gul H, Hamayun M, Nangyal H, Fazal I. 2014. Influence of sodium chloride on growth and chemical composition of Tagetes erecta. South Asian Journal of Life Sciences 2:29-32.

Schiop ST, Al Hassan M, Sestras AF, Boscaiu M, Sestras RE, Vicente O. 2015. Identification of salt stress biomarkers in Romanian Carpathian populations of Picea abies (L.) Karst. PLoS ONE 10: e0135419. DOI:10.1371/journal.pone.0135419.

Serrato-Cruz MA. 2004. Colecta, caracterización y aprovechamiento de Tagetes erecta L. como ornamental. Avances. Metodología de Investigación. Chapingo, Mexico: Departamento de Fitotecnia, Universidad Autónoma Chapingo, 1-109.

Shinde NV, Kanase KG, Shilimkar VC, Undale VR, Bhosale AV. 2009. Antinociceptive and anti-Inflammatory effects of solvent extracts of Tagetes erectus Linn (Asteraceae). Tropical Journal of Pharmaceutical Research 8:325-329. 
668 Siddiqui MH, Al-Khaishany MY, Al-Qutami MA, Al-Whaibi MH, Grover A, Ali HM, Al-

669

670

671

672

673

674

675

676

677

678

679

680

681

682

683

684

685

686

687

688

689

690

691

692

693

694

695

696

697

Wahibi MS, Bukhari NA. 2015. Response of different genotypes of faba bean plant to drought stress. International Journal of Molecular Sciences 16:10214-10227. DOI:10.3390/ijms160510214.

Smirnoff N, Cumbes QJ. 1989. Hydroxyl radical scavenging activity of compatible solutes. Phytochemistry 28:1057-1060.

Sofo A, Dichioa B, Xiloyannisa C, Masia A. 2004. Lipoxygenase activity and proline accumulation in leaves and roots of olive trees in response to drought stress. Physiologia Plantarum 12:158-165.

Szabados L, Savouré A. 2010. Proline: a multifunctional amino acid. Trends in Plant Science 15:89-97.

Talukdar D. 2013. Comparative morpho-physiological and biochemical responses of lentil and grass pea genotypes under water stress. Journal of Natural Science, Biology and Medicine 4:396-402.

The Plant List. 2013. Version1.1. Available at http://www.theplantlist.org (accessed 12 January 2016)

Valdez-Aguilar LA, Grieve CM, Poss J. 2009. Salinity and alkaline pH in irrigation water affect marigold plants I. Growth and shoot dry weight partitioning. Hortscience 44:1719-1725.

Van Breusegem F, Dat JF. 2006. Reactive oxygen species in plant cell death. Plant Physiology 141:384-390.

Vasudevan P, Sharma S, Kashyap S. 1997. Tagetes: A multipurpose plant. Bioresource Technology 62:29-35.

Verbruggen N, Hermans C. 2008. Proline accumulation in plants: a review. Amino Acids 35:753-759.

Vicente O, Boscaiu M, Naranjo MA, Estrelles E, Bellés JM, Soriano P. 2004. Responses to salt stress in the halophyte Plantago crassifolia (Plantaginaceae). Journal of Arid Environments 58:463-481.

Yang L, Fountain JC, Wang H, Ni X, Ji P, Lee RD, Kemerait RC, Scully BT, Guo B, 2015. Stress sensitivity is associated with differential accumulation of reactive oxygen and nitrogen species in maize genotypes with contrasting levels of drought tolerance. 
698 International Journal of Molecular Sciences 16, 24791-24819. 699 DOI:10.3390/ijms161024791.

700 Zhishen J, Mengcheng T, Jianming W. 1999. The determination of flavonoid contents in 701 mulberry and their scavenging effects on superoxide radicals. Food Chemistry 64:555$702 \quad 559$.

703 